\title{
Smoking Cessation in Chronic Obstructive Pulmonary Disease
}

\author{
An Effective Medical Intervention
}

\section{Stefan Andreas, Thomas Hering, Stephan Mühlig, Dennis Nowak, Tobias Raupach, Heinrich Worth}

\begin{abstract}
SUMMARY
Background: As many as $50 \%$ of older smokers develop chronic obstructive pulmonary disease (COPD), and more than $80 \%$ of COPD-associated morbidity is caused by tobacco smoking. Despite the severe symptoms from which COPD patients suffer, they are often unable to quit smoking on their own.
\end{abstract}

Methods: Experts from 9 medical societies, under the aegis of the German Society of Pulmonology and Respiratory Medicine (Deutsche Gesellschaft für Pneumologie und Beatmungsmedizin), have developed an S3 guideline on smoking cessation in COPD. They took previously published guidelines into account, as well as more than 2000 initially surveyed publications, and created the new guideline in two consensus conferences followed by a Delphi process.

Results: The following strongly evidence-based statements can be made: A smoking cessation strategy based on a combination of medication and psychosocial support has been found to be effective in COPD patients. Smoking cessation improves pulmonary function, alleviates dyspnea and cough, reduces the frequency of COPD exacerbations, and lowers mortality. Mere smoking reduction does not improve pulmonary function or alleviate symptoms. Smoking cessation is the most effective and least expensive single means of lowering the risk of developing COPD and of arresting its progression. Smoking cessation should therefore be strongly promoted at all levels of health care delivery.

Conclusions: There is no question that smoking cessation ranks among the most effective medical interventions, yet the German health care system still does not assign it an adequate priority. Dtsch Arztebl Int 2009; 106(16): 276-82 DOI: $10.3238 /$ arztebl.2009.0276

Key words: nicotine withdrawal, chronic obstructive pulmonary disease, evidence-based medicine, smoking, addiction

Lungenfachklinik Immenhausen: Prof. Dr. med. Andreas

Pneumologe, Berlin: Dr. med. Hering

Klinische Psychologie, Technische Universität Chemnitz: Prof. Dr. phil. Mühlig

Institut für Arbeits-, Sozial-und Umweltmedizin, Universitätsklinikum München: Prof. Dr. med. Nowak

Abteilung Kardiologie und Pneumologie, Universitätsmedizin Göttingen: Dr. med. Raupach

Medizinische Klinik I, Klinikum Fürth: Prof. Dr. med. Worth
1 ccording to the microcensus surveys, one third of Germany's population are smokers. About $50 \%$ of male smokers and a third of female smokers reported that they consumed more than 20 cigarettes daily. The average age from which regular smoking is taken up is 13-14 years. In the European Union, Germany is one of the countries with the highest tobacco consumption $(1,2)$. The overwhelming majority of smokers (80\% to $90 \%$ ) wants to quit smoking in principle but is unable to do so because of the strong addictive properties of tobacco $(3,4)$. Some $30 \%$ of smokers make at least one serious attempt in a 12 month period to quit smoking. This is successful in less than $5 \%$ of cases over the following 12 months.

Tobacco smoke is the main risk factor for chronic obstructive pulmonary disease (COPD; relative risk 13) $(5,6)$. Up to $50 \%$ of older smokers develop COPD (7), and $80 \%$ to $90 \%$ of COPD morbidity is caused by tobacco smoking. Worldwide, COPD is currently the fifth most common cause of death, and the trend is strongly increasing (1). According to recent studies, $8 \%$ to $13 \%$ of the adult population in Europe and North America have developed COPD $(5,8)$. The economic costs due to COPD are substantial and are estimated at far in excess of 10 billion euros per year (9). Quitting tobacco consumption has positive effects even in clinically manifest COPD. Many publications point out that smoking cessation is possible and effective in patients with COPD.

Against this background, an S3 clinical practice guideline for smoking cessation in patients with COPD has been developed under the aegis of the German Society for Pneumology and Respiratory Medicine (Deutsche Gesellschaft für Pneumologie und Beatmungsmedizin, DGP).

\section{Development of the guideline}

The guideline's development took from 2005 to early 2008. Altogether 16 experts from 9 specialist medical societies set out the core statements according to defined criteria (box 1). The $\mathrm{S} 3$ guideline is based on a systematic review of the literature and an interdisciplinary consensus process.

According to international attempts to cooperate and divide up the work involved in guideline development, the expert panel decided to review existing, current, 
BOX 1

\section{Participating experts, specialist/expert societies,} and institutions

(1) German Society for Pneumology and Respiratory Medicine (DGP)

(2) Wissenschaftlicher Aktionskreis Tabakentwöhnung (WAT) e.V. (Research Action Group Tobacco Cessation)

(3) German Society for Psychiatry, Psychotherapy and Neurology (DGPPN)

(4) German Society for Addiction Research and Addiction Treatment (DG-Sucht)

(5) Selbsthilfegruppe Patientenliga Atemwegserkrankungen e.V. (patients' self help group for respiratory diseases)

(6) German Society of General Practice and Family Medicine (DEGAM)

(7) German Society for Internal Medicine (DGIM)

(8) German Federal Association of Pneumologists (BDP)

(9) Barmer Ersatzkasse (a large health insurer)

(10) Special interest group "Clinical psychology" of the German Psychological Society (DGPS)

(11) Institute for Theoretical Surgery, Philipps University Marburg

(12) German Respiratory League

The numbers of parentheses relate to specialist/expert society memberships

Professor Dr Stefan Andreas (1)

Professor Dr Anil Batra $(2,3,4)$

Professor Dr Juergen Behr (1)

Dr Helmut Berck (5)

Dr Jean-Francois Chenot (6)

Professor Dr Adrian Gillissen (7)

Dr Thomas Hering (8)

Professor Dr Felix Herth (1)

Dr Rüdiger Meierjürgen (9)

Professor Dr Stephan Mühlig (10)

Professor Dr Dennis Nowak (1)

Professor Michael Pfeifer (1)

Dr Tobias Raupach (1)

Dr Konrad Schultz (1)

PD Dr Helmut Sitter (11)

Professor Dr H Worth (12)

\section{BOX 2}

\section{Tobacco smoking causes a multitude of pulmonary diseases}

Respiratory and pulmonary diseases primarily caused by smoking or in which smoking unfavourably influences progression

- COPD: chronic obstructive bronchitis, emphysema

- Lung cancer

\section{Further diseases of the respiratory tract and lung}

\section{Chronic inflammatory disorders of the bronchi}

- Bronchial asthma

- Alpha-1 antitrypsin deficiency emphysema

- Chronic (non-obstructive) bronchitis

\section{Malignant neoplasms}

- Cancer of the paranasal sinus

- Cancer of the mouth

- Cancer of the larynx

Infectious diseases

- Rhinitis, sinusitis, laryngitis

- Pneumonia

- Influenza

- Tuberculosis

\section{Interstitial lung disease}

- Pneumoconioses

- Idiopathic lung fibrosis

- Desquamative interstitial pneumonia

- Respiratory bronchiolitis-associated interstitial lung disease

Citations and meta-analyses were assessed by following the categories set out by the Oxford Centre for Evidencebased Medicine (10), ranging from 1 (=meta-analysis of randomized studies or randomized study) to 5 (=expert opinion). The process of transformation into evidence levels and levels of recommendation were undertaken by referring to the categories in the current method report on national disease management guidelines (11):

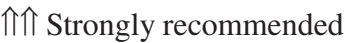

$\Uparrow$ Recommended

$\Leftrightarrow$ Open recommendation.

In 2 consensus conferences of 2 days each, which Dr Sitter moderated, the core statements and the copy were set out while taking into account the underlying evidence. Finally the guideline was again subjected to a Delphi procedure.

The guideline's development was financially supported by the German Society for Pneumology and Respiratory Medicine (DGP). Part of the funding came from 
membership contributions and donations, another part from the annual general meeting. All experts worked as unpaid volunteers and did not receive any honoraria (box 1).

The complete guideline was published in 2008 (12). The guideline, the report on the methods, and the version for patients are available from the homepage of the AWMF (www.awmf-leitlinien.de)

\section{Results}

\section{Tobacco smoking as an addiction}

In humans or animals that have taken in nicotine for a lengthy period of time, withdrawal may result in symptoms such as:

-Dysphoria
-Insomnia and disturbed sleep
-Depression
-Restlessness
-Motor unrest
-Anxiety
-Increased appetite
-Poor concentration.

A recent British study showed that smoking even one cigarette only, at the age of 11 , resulted in double the adjusted relative risk of taking up regular smoking 3 years later (13). This shows how strongly addictive nicotine is, especially in adolescents (e10).

The clear majority of smokers (80\% to $90 \%$ ) want to stop smoking in principle $(3,4)$. Only $30 \%$ undertake at least one serious attempt within 12 months to stop smoking. This attempt is successful in less than $5 \%$ of cases if unsupported. Nicotine inhaled in tobacco smoke has the characteristics of a drug with a highly addictive potential (evidence level 1).

\section{Smoking as a trigger of a multitude of pulmonary disorders}

Cigarette smoke is a heterogeneous aerosol consisting of more than 4000 substances, which is released when tobacco is incompletely burnt. It triggers a complex change of the cellular and humoral immune response, which ultimately facilitates respiratory and systemic infections and impairs the immunological control of mutations. Box 2 summarizes the main pulmonary disorders that arise from tobacco smoking.

\section{Tobacco smoking as a cause of COPD}

Worldwide, COPD is the fifth most common cause of death, and the trend is strongly increasing (1). Some $8 \%$ to $13 \%$ of the adult population of Europe and North America is affected by COPD, according to recent studies $(5,8)$. In a proportion of the affected patients, the disease remains undiagnosed, and they are not aware of their condition. In patients with dyspnea, pneumological disorders are considered too rarely (8).

With a relative risk of 13 , tobacco smoking is the main risk factor for $\operatorname{COPD}(5,6)$. This means that tobacco smoking increases the risk of developing COPD 13-fold. Up to $50 \%$ of older smokers develop COPD (7). $80 \%$ to $90 \%$ of COPD morbidity is due to tobacco smoking (5-7).

COPD is a systemic disease. That means that it causes a range of extrapulmonary changes, which include

\section{FIGURE}

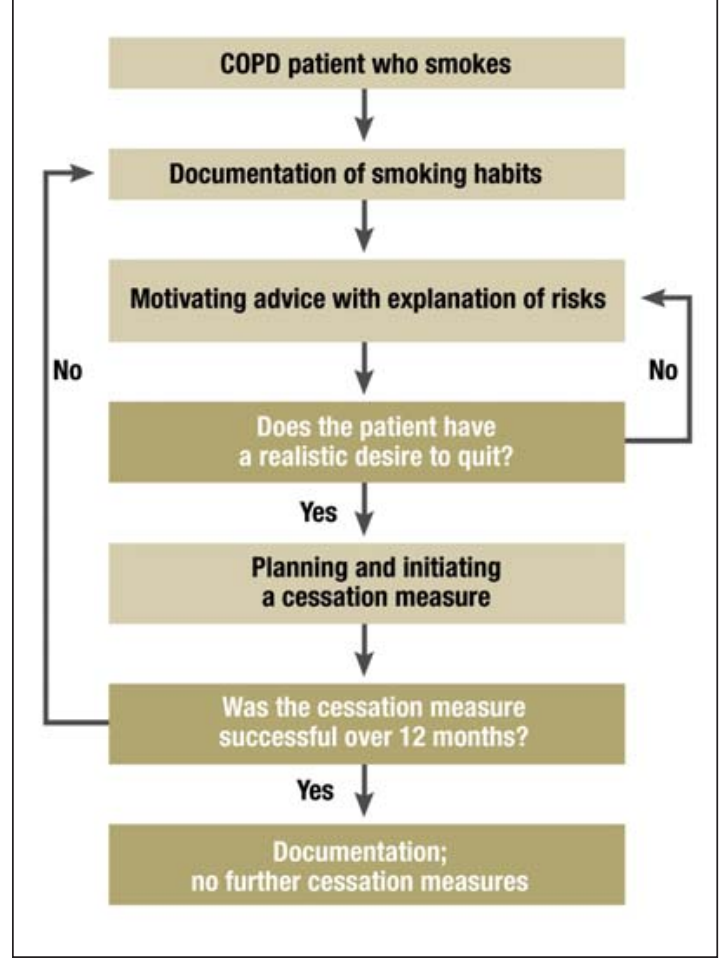

Management of patients who smoke with chronic obstructive pulmonary disease (from: Andreas S, Batra A, Behr J, et al: Tabakentwöhnung bei COPD [smoking cessation in COPD]. S3 guideline published by the German Society for Pneumology and Respiratory Medicine. Pneumologie 2008; 62: 255-72 (12). (With permission from ThiemeVerlag, Stuttgart) cardiac, muscular, bone related, psychological, and social sequelae. These associations are mediated by the pronounced systemic inflammation and neurohumoral activation (14).

Many large epidemiological cross sectional and longitudinal studies have shown that smoking affects lung function (15). Smoking during adolescence reduces the increase in lung volume during the physical growth spurts and thus inhibits the forced expiratory volume in 1 second (FEV1) in later life (e11). FEV1 is the volume of air that a patient can expel using all their force within 1 second (lung function test).

\section{Passive smoking as a cause of COPD}

In Germany, $27 \%$ of the non-smoking population is regularly exposed to passive smoking in the workplace or during leisure activities (2). Epidemiological data that were collected before the legislation to protect nonsmokers came into force show that 3000-4000 nonsmokers in Germany die from the consequences of passive smoke exposure every year (16). More than 900 non-smokers die as a result of COPD caused by passive smoking (16). Passive smoking is a risk factor for the development of COPD (evidence level 1). This has consequences, among others, for the recognition of occupational disorders.

\section{Tobacco smoking in COPD patients}

In spite of their severe symptoms, only some COPD patients manage to give up smoking. Among COPD 
BOX 3

\section{Structure of consultation using the 5A (adapted from 18)}

- Ask smoking status

- Advise smoking cessation

- Assess motivation for quitting

- Assist smoking cessation

- Arrange aftercare

(from: Andreas S, Batra A, Behr J, et al: Tabakentwöhnung bei COPD [smoking cessation in COPD]. S3 guideline published by the German Society for Pneumology and Respiratory Medicine. Pneumologie 2008; 62: 255-72 (12) (With permission from Thieme-Verlag, Stuttgart)

\section{BOX 4}

\section{Smoking cessation has a positive effect on}

- Lung function, especially FEV1

- Diffusion capacity

- Dyspnea

- Coughing

- Sputum production

- Wheezing

- Bronchial hyperreactivity

- Respiratory inflammation/infection

- Exacerbation rate

- Mortality

From: Andreas S, Batra A, Behr J, et al: Tabakentwöhnung bei COPD [smoking cessation in COPD]. S3 guideline published by the German Society for

Pneumology and Respiratory Medicine. Pneumologie 2008; 62: 255-72 (12). (With permission from Thieme-Verlag, Stuttgart)

patients, the proportion of active smokers is notably higher than in the general population (8). A chronic respiratory disorder increases the risk for depression (e12), and smoking can assume the character of self medication in patients with latent depression (smoking and nicotine as antidepressants) (e13). These associations explain why COPD patients find it difficult to stop smoking. Smoking patients with COPD have a particularly high nicotine dependency (evidence level 2). Integrated approaches to smoking cessation are therefore required.

\section{Diagnosis/questionnaire}

A complete smoking history is a prerequisite for providing support and motivation in smoking cessation for COPD patients. This history results in a higher number of patients who successfully cease smoking, but it is currently not taken often enough. Tobacco consumption should therefore be assessed and documented regularly (level of recommendation $\Uparrow \Uparrow$, that is: strongly recommended).
To determine the extent of dependence, the Fagerström test for nicotine dependence (FTND) is particularly suitable (e14). Of 6 questions, the 2 main ones are:

- How soon after you wake up do you smoke your first cigarette?

- How many cigarettes do you smoke each day?

The FNDT is an appropriate measuring instrument for predicting short term and long term abstinence after smoking cessation (18). The additional structured documentation of a possibly depressed mood/disposition is advisable-for example, with the HADSd questionnaire (HADS, Hospital Anxiety and Depression Scale).

\section{Motivational advice}

COPD patients tend to be open to a doctor's advice to stop smoking (figure). The recommendation is particularly effective if an association is made between symptoms of COPD or pathological medical findings and tobacco consumption (e15-e17). Controlled studies have shown that explaining lung function is particularly effective in this context. The consultation can be formalized by referring to the $5 \mathrm{~A}$ ( box 3 ).

The motivational intevention can be used if a smoker is not prepared to primarily agree to quit smoking. The motivational interview is a technique for modifying dependent behaviors and was initially used successfully in alcohol cessation strategies (e18). The concept of the motivational interview requires critical reflection of the role of the advisor, which should be as follows:

- Asking open questions

- Active listening (empathy)

- Respect for the other person's behavior

- Summarizing what has been said

- Handle resistance flexibly

- Teasing out "self motivating" answers.

A recent study has shown that the motivational interview conducted by the general practitioner was 5 times as effective as traditional exhortations to stop smoking (e18). However, the motivational interview does take longer.

\section{Positive effects of smoking cessation}

In prospective, controlled, and randomized studies, smoking cessation resulted in a halving of the annual loss in FEV1 (e19). In the first year after quitting smoking, the FEV1 even increases (e19). Even after 11 years, the annual FEV1 decline in the group of successful quitters was notably below that of the group of continuing smokers (19). To put it in a different way, in 1 of 3 smokers with medium grade COPD, quitting smoking can prevent progression to severe or very severe COPD in the following 3 years (8). Further, smoking cessation reduces mortality and hospital admissions significantly (box 4).

\section{Smoking reduction is no alternative to smoking cessation}

Many studies have shown that reducing smoking has no clinically relevant effect with regard to the progression of COPD (annual FEV1 reduction) (e19-e21). 


\section{Pharmacotherapy in smoking cessation}

\begin{tabular}{|c|c|c|c|}
\hline Substance & Mode of application & Dosage & Special remarks \\
\hline \multirow[t]{5}{*}{ Nicotine } & Patch & $\begin{array}{l}3 \text { strengths } \\
\text { (preparations differ by manufacturer) } \\
\text { To be used over } 16 \text { or } 24 \text { hours }\end{array}$ & $\begin{array}{l}\text { Combination therapy with other nicotine replacement } \\
\text { preparations possible } \\
\text { Undesirable side effect: skin reaction }\end{array}$ \\
\hline & Chewing gum & $\begin{array}{l}2 \mathrm{mg}, 4 \mathrm{mg} \\
\text { Maximum daily dosage: } \\
25 \text { pieces ( } 2 \mathrm{mg} \text { ) or } 15 \text { pieces }(4 \mathrm{mg})\end{array}$ & $\begin{array}{l}\text { Problematic in patients wearing dentures } \\
4 \mathrm{mg} \text { : especially to prevent weight gain } \\
\text { and in heavy smokers (>20/day). } \\
\text { Undesirable side effects: heartburn, oral irritation }\end{array}$ \\
\hline & Sublingual lozenge & $\begin{array}{l}2 \mathrm{mg} \\
\text { Maximum daily dosage } 30 \text { lozenges }\end{array}$ & $\begin{array}{l}\text { Rapid onset of effect } \\
\text { Undesirable side effect: oral irritation }\end{array}$ \\
\hline & Lozenge & $\begin{array}{l}1 \mathrm{mg}, 2 \mathrm{mg}, 4 \mathrm{mg} \text {, maximum daily } \\
\text { dosage } 30 \text { lozenges ( } 2 \mathrm{mg} \text { lozenge) }\end{array}$ & $\begin{array}{l}\text { Rapid onset of effect } \\
\text { Undesirable side effect: oral irritation }\end{array}$ \\
\hline & Nasal spray & $\begin{array}{l}0.5 \mathrm{mg} \text { per actuation, } 1 \text { actuation } \\
\text { in each nostril } \\
\text { Maximum dosage twice per hour }\end{array}$ & $\begin{array}{l}\text { Available on prescription only; in Germany available } \\
\text { only from international pharmacies } \\
\text { Undesirable side effects: irritation of the mucosa, } \\
\text { potential for dependence }\end{array}$ \\
\hline Varenicline & Tablet & $\begin{array}{l}0.5 \mathrm{mg} 1 \times \text { daily for } 3 \text { days, } \\
0.5 \mathrm{mg} 2 \times \text { daily for } 4 \text { days, } \\
\text { followed by quitting smoking, } \\
\text { followed by } 1 \mathrm{mg} 2 \times \text { daily for } \\
\text { at least } 11 \text { weeks }\end{array}$ & $\begin{array}{l}\text { No completed study in COPD } \\
\text { Undesirable side effects: nausea, vivid dreams }\end{array}$ \\
\hline Bupropion & Tablet & $\begin{array}{l}150 \mathrm{mg} 1 \mathrm{x} \text { daily for } 7 \text { days, } \\
\text { followed by quitting smoking, } \\
\text { followed by } 150 \mathrm{mg} 2 \mathrm{x} \text { daily } \\
\text { Total duration of treatment: } \\
8 \text { weeks }\end{array}$ & $\begin{array}{l}\text { Undesirable side effects: cerebral seizures (frequency } \\
1 \text { in 1000), nausea, sleep disturbances }\end{array}$ \\
\hline
\end{tabular}

Compensation mechanisms are assumed to be responsible, owing to which changed smoking behavior (deeper and longer inhalation) cancels out the effect of a lower number of consumed cigarettes (e19, e21). An improvement in lung function and other problems is not to be expected if tobacco consumption is merely reduced (evidence level 2 ).

\section{Integrated approach, smoking cessation program}

COPD patients who smoke have a particularly high degree of nicotine dependence, as explained earlier. This requires structured smoking cessation programs that comprise drug interventions as well as non-drug interventions $(20,21)$. The non-drug or psychosocial intervention consists in particular of a structured smoking cessation program over several hours (21). Since symptomatic smokers have a particularly high motivation for stopping smoking when they identify smoking itself as the cause of their symptoms (e22, e23), a multimodal cessation concept should consider cognitive and addictive aspects, but also subjective respiratory problems and objective findings, such as the lung function.

The following statements can be deduced from a Cochrane review on smoking cessation in COPD patients and from additional current literature $(19,21)$ : A smoking cessation concept that includes medication and psychosocial support has been shown to be effective for COPD patients (evidence level 1). Studies of the efficacy of psychosocial support alone in COPD patients are currently lacking.

\section{Medication treatment}

Supporting psychosocial treatments with medication increases the prospects of patients for abstinence substantially. The following medication approaches have become established (table):

\section{Nicotine replacement therapy}

Nicotine replacement therapy aims to alleviate withdrawal symptoms and cravings by means of temporary, controlled nicotine administration via an innocuous carrier medium. The nicotine replacement products on the market are available from pharmacies only, but they do not require a presciption (one exception is nicotine nasal spray, which in Germany requires a prescription and is available only from international pharmacies). Nicotine replacement therapy roughly doubles the success rate of smoking cessation (22). In heavy smokers, a combination of patches and, for example, chewing gum is indicated.

\section{Varenicline}

Varenicline is a partial nicotine agonist. It is licensed in Germany for the treatment of tobacco dependence. 
Varenicline is available only from pharmacies and requires a prescription but will not be reimbursed by the health insurers. Varenicline is more effective than bupropion, with an odds ratio (OR) of 1.7 (95\% confidence interval $[\mathrm{CI}] 1.3$ to 2.2 ) compared with bupropion (23). Named side effects include vertigo/dizziness, nausea, vivid dreams, headache, vomiting, sleeplessness, and flatulence. The substance is often prescribed internationally and for this reason is included here, although studies for COPD patients are currently lacking.

\section{Bupropion}

For patients with COPD, two studies have shown efficacy after 6 months (24). In a general smokers' cohort the success rate doubled due to bupropion treatment (OR 2.06, CI 1.77 to 2.40). Side effects during treatment with bupropion may include sleep disturbances, dizziness, and dry mouth. The risk of epileptic seizures is increased; any contraindications should therefore be strictly observed.

\section{Health economic aspects}

On the basis of publications $(6,25)$, the cost of smoking cessation can be calculated at 300 to 1200 euros per year of life gained. The cost per year of life gained for hemodialysis in chronic renal failure, for example, amounts to 60000 euros; for surgical myocardial revascularization, to 20000 euros; and for medical treatment of arterial hypertension, 50000 euros (e 24). Smoking cessation is the most effective and cost effective individual measure for reducing the risk of COPD developing and for stopping disease progression (evidence level 1). Smoking cessation should therefore be promoted and supported at

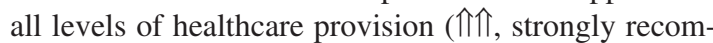
mended).

In spite of all this, smoking cessation is not regarded as a great priority in Germany's healthcare system. Classifying medication treatments to aid cessation as non-reimbursable lifestyle preparations in $\$ 34$ German Social Code V and the medication guideline does not meet the requirements of evidence based medicine.

\section{Conclusion}

In Germany, smoking cessation is marginalized, which is inconsistent with the data situation and experiences internationally. This has substantial consequences for the healthcare system's ability to deliver.

A smoking cessation plan that includes medication therapy and psychosocial support has been shown to be very effective in patients with COPD.

\section{Acknowledgement}

The authors thank the German Society for Pneumology and Respiratory Medicine (DGP) for financial support for a secretary and the consensus conferences.

\section{Conflict of interest statement}

Professor Andreas has received honoraria for speaking and clinical studies on smoking cessation from Pfizer.

Dr Hering has received honoraria for advisory activities and speaking on smoking cessation from Pfizer, Pharmacia, Novartis, and Johnson \& Johnson. Professor Nowak has received honoraria for speaking in connection with smoking cessation events from Pfizer and GSK.
Dr Raupach has received honoraria for speaking and clinical studies on smoking cessation from Pfizer.

Professor Worth has received honoraria for speaking on COPD management for doctors and patients from GSK and Pfizer.

Professor Mühlig declares that no conflict of interest exists according to the guidelines of the International Committee of Medical Journal Editors. Manuscript received on 12 February 2009, revised version accepted on 18 February 2009

Translated from the original German by Dr Birte Twisselmann.

\section{REFERENCES}

1. Tonnesen P, Carrozzi L, Fagerstrom KO, Gratziou C et al.: Smoking cessation in patients with respiratory diseases: a high priority, integral component of therapy. Eur Respir J 2007; 29: 390-417.

2. Janson C, Künzli N, deMarco R al.: Change in active and passive smoking in the EU respiratory health survey. Eur Respir J 2006; 27: 517-24.

3. Nelson CB, Wittchen HU: Smoking and nicotine dependence. Results from a sample of 14- to 24-year-olds in Germany. Eur Addict Res 1998; 4: 42-9.

4. Center disease control: Cigarette smoking among adults_-United States, 1995. MMWR Morb Mortal Wkly Rep 1997; 46: 1217-20.

5. ASPECT Consortium: Tobacco or health in the European Union. Belgien: European Commission 2004; 1-295.

6. Doll R, Peto R, Boreham J, Sutherland I: Mortality in relation to smoking: 50 years' observations on male British doctors. Bmj 2004; 328: 1519.

7. Lokke A, Lange P, Scharling H, Fabricius P et al.: Developing COPD: a 25 year follow up study of the general population. Thorax 2006; 61: 935-9.

8. Shahab L, Jarvis MJ, Britton J, West R: Prevalence, diagnosis and relation to tobacco dependence of chronic obstructive pulmonary disease in a nationally representative population sample. Thorax 2006; 61: 1043-7.

9. Crieé C-P, Novak D: Einsparpotential durch Prävention bei COPD, in Zukunft sichern. In: Schauder P et al. (eds.): Senkung der Zahl chronisch Kranker, Verwirklichung einer realistischen Utopie. Köln: Deutscher Ärtzeverlag 2006; 205-8.

10. Phillips B, Ball C, Sackett D: Levels of evidence, www.cebm.net/ index.aspx?0=1025. 2001, Oxford Centre for Evidence-based Medicine.

11. Bundesärztekammer (BÄK), Arbeitsgemeinschaft der Wissenschaftlichen Medizinischen Fachgesellschaften (AWMF), Kassenärztliche Bundesvereinigung (KBV): Nationales Programm für VersorgungsLeitlinien. Methoden-Report 2004.

12. Andreas S, Batra A, Behr J et al.: Tabakentwöhnung bei COPD. S3 Leitlinie herausgegeben von der Deutschen Gesellschaft für Pneumologie und Beatmungsmedizin. Pneumologie 2008; 62: 255-72.

13. Fidler JA, Wardle J, Brodersen NH, Jarvis MH et al.: Vulnerability to smoking after trying a single cigarette can lie dormant for three years or more. Tob Control 2006; 15: 205-9.

Key messages

- Nicotine inhaled in tobacco smoke has the characteristics of a drug with a highly addictive potential.

- Tobacco consumption should regularly be assessed and documented.

- Patients with chronic obstructive pulmonary disease (COPD) who still smoke should be motivated to quit smoking, independent of age and in a clear manner relating to them individually.

- Smoking cessation positively affects symptoms, progression of lung function, and mortality in patients with COPD. 
14. Andreas S, Anker SD, Scanlon PD: Somers VK, Neurohumoral activation as a link to systemic manifestation of chronic lung disease. Chest 2005; 128: 3618-24.

15. Fletcher $\mathrm{C}$, Peto $\mathrm{R}$, The natural history of chronic airflow obstruction. Br Med J 1977; 1: 1645-8.

16. Lifting the smoke screen-10 reasons for a smoke free Europe. Brussels: European Respiratory Society 2006; $28 \mathrm{ff}$.

17. Batra A, Lindinger P, Schütz C: Tabakbedingte Störungen „Leitlinie Tabakentwöhnung“. Arbeitsgemeinschaft der Wissenschaftlichen Medizinischen Fachgesellschaften 2004

18. Fiore MC: Treating tobacco use and dependence: an introduction to the US Public Health Service Clinical Practice Guideline. Respir Care 2000; 45: 119.

19. Anthonisen NR, Skeans MA, Wise RA, Manfreda J et al.: The effects of a smoking cessation intervention on 14.5-year mortality: a randomized clinical trial. Ann Intern Med 2005; 142: 233-9.

20. Wagena EJ, Zeegers MP, van Schayck CP, Wouters EF: Benefits and risks of pharmacological smoking cessation therapies in chronic obstructive pulmonary disease. Drug Saf 2003; 26: 381-403.

21. van der Meer RM, Wagena EJ, Ostelo RW, Jacobs JE et al.: Smoking cessation for chronic obstructive pulmonary disease. Cochrane Database Syst Rev 2003: CD002999.
22. Silagy C, Lancaster T, Stead L, Mant D et al.: Nicotine replacement therapy for smoking cessation. Cochrane Database Syst Rev 2004: CD000146.

23. Cahill K, Stead LF, Lancaster T: Nicotine receptor partial agonists for smoking cessation. Cochrane Database Syst Rev 2007: CD006103.

24. Wagena EJ, Knipschild PG, Huibers MJH, Wouters EFM, et al.: Efficacy of bupropion and nortriptyline for smoking cessation among people at risk for or with chronic obstructive pulmonary disease. Arch Intern Med 2005; 165: 2286-92.

25. Felten D, Raupach T, Sessler C, Lüthje L et al.: Efficacy of a cognitivebehavioral program with pharmacological support to achieve smoking cessation. Dtsch Med Wochenschr 2006; 131: 197-202.

Corresponding author

Prof. Dr. med. Stefan Andreas

Lungenfachklinik Immenhausen/Kreis Kasse

Pneumologische Lehrklinik der Universität Göttingen

Robert Koch Str. 3

34376 Immenhausen, Germany

sandreas@lungenfachklinik-immenhausen.de 


\title{
Smoking Cessation in Chronic Obstructive Pulmonary Disease
}

\author{
An Effective Medical Intervention
}

Stefan Andreas, Thomas Hering, Stephan Mühlig, Dennis Nowak, Tobias Raupach, Heinrich Worth

\section{E-REFERENCES}

e1. Pauwels R, A Buist, P Calverley, C Jenkins et al.: Global strategy for the diagnosis, management, and prevention of chronic obstructive pulmonary disease. NHLBI/WHO Global Initiative for Chronic Obstructive Lung Disease (GOLD) Workshop summary. Am J Respir Crit Care Med 2001; 163: 1256-76.

e2. Rabe KF, S Hurd, A Anzueto, PJ Barnes et al.: Global strategy for the diagnosis, management, and prevention of chronic obstructive pulmonary disease: GOLD executive summary. Am J Respir Crit Care Med 2007; 176: 532-55.

e3. Aigner K, Homeier I, Koessler W, Zwick H et al.: Standards der Raucherentwöhnung, Konsensus der ÖGP. Wiener Klinische Wochenschrift 2005; 117: Supplement 2, 1-22.

e4. National Health Committee: Guidelines for Smoking Cessation. Wellington, New Zealand 2004.

e5. National Collaborating Centre for Chronic Conditions NIoCE (NICE): Chronic obstructive pulmonary disease. National clinical guideline on management of chronic obstructive pulmonary disease in adults in primary and secondary care. Thorax 2004; 59: 1-232.

e6. West R, McNeill A, Raw M: Smoking cessation guidelines for Scotland: 2004 update. NHS Health Scotland and ASH Scotland 2004.

e7. Anderson JE, Jorenby DE, Scott WJ, Fiore MC: Treating tobacco use and dependence: an evidence-based clinical practice guideline for tobacco cessation. Chest 2002; 121: 932-941.

e8. Empfehlungen zur Therapie der Tabakabhängigkeit. Arzneimittelkommission der deutschen Ärzteschaft. Suchtmed 2001; 3: 156-75.

e9. Parrott S C Godfrey: Economics of smoking cessation. BMJ 2004; 328: 947-9.

e10. Watkins SS, Koob GF, Markou A: Neural mechanisms underlying nicotine addiction: acute positive reinforcement and withdrawal. Nicotine Tob Res 2000; 2: 19-37.

e11. Gold DR, Wang X, Wypij D, Speizer FE et al.: Effects of cigarette smoking on lung function in adolescent boys and girls. N Engl J Med 1996; 335: 931-7.

e12. Wagena EJ, van der Meer RM, Ostelo RJ, Jacobs JE et al.: The efficacy of smoking cessation strategies in people with chronic obstructive pulmonary disease: results from a systematic review. Respir Med 2004; 98: 805-15.

e13. Hughes J, Stead L, Lancaster T: Antidepressants for smoking cessation. Cochrane Database Syst Rev 2004: CD000031.

e14. Heatherton TF, Kozlowski LT, Frecker RC, Fagerstrom KO: The fagerstrom test for nicotine dependence: a revision of the Fagerstrom Tolerance Questionnaire. Br J Addict 1991; 86: 1119-27.

e15. West R, McNeill A, Raw M: Smoking cessation guidelines for health professionals: an update. Health Education Authority. Thorax 2000; 55: 987-99.

e16. Hilberink SR, Jacobs JE, Schlosser M, Grol RP et al.: Characteristics of patients with COPD in three motivational stages related to smoking cessation. Patient Educ Couns 2006; 61: 449-57.

e17. Bize R, Burnand B, Mueller Y, Cornuz J: Biomedical risk assessment as an aid for smoking cessation. Cochrane Database Syst Rev 2005: CD004705.

e18. Soria R, Legido A, Escolano C, Lopez Yeste A et al.: A randomised controlled trial of motivational interviewing for smoking cessation. Br J Gen Pract 2006; 56: 768-74.

e19. Scanlon PD, Connett JE, Waller LA, Altose MD et al.: Smoking cessation and lung function in mild-to-moderate chronic obstructive pulmonary disease. The Lung Health Study. Am J Respir Crit Care Med 2000; 161: 381-90.

e20. Godtfredsen NS, Vestbo J, Osler M, Prescott E: Risk of hospital admission for COPD following smoking cessation and reduction: a Danish population study. Thorax 2002; 57: 967-72.

e21. Simmons MS, Connett JE, Nides MA, Lindgren PG et al.: Smoking reduction and the rate of decline in FEV(1): results from the Lung Health Study. Eur Respir J 2005; 25: 1011-7.

e22. Bednarek M, Gorecka D, Wielgomas J, Czajkowska-Malinowska M et al.: Smokers with airway obstruction are more likely to quit smoking. Thorax 2006.

e23. Walters N, Coleman T: Comparison of the smoking behaviour and attitudes of smokers who attribute respiratory symptoms to smoking with those who do not. Br J Gen Pract 2002; 52: 132-4.

e24. Parrott S, Godfrey C, Raw M: Costs of employee smoking in the workplace in Scotland. Tob Control 2000; 9: 187-92. 